\title{
Lifestyle Modification Practice and Associated Factors among Diagnosed Hypertensive Patients in Selected Hospitals in West Arsi Zone, Oromia Regional State, Ethiopia
}

Hika Wakjira ( $\sim$ hikawakjira@gmail.com )

West Arsi Zone health Office ,Oromia region, Ethiopia

Tesfaye Gobena

Haramaya University

Hirbo Shore

Haramaya University

\section{Research Article}

Keywords: Lifestyle modification, Hypertension, practices, Ethiopia

Posted Date: March 2nd, 2021

DOl: https://doi.org/10.21203/rs.3.rs-244665/v1

License: (c) (1) This work is licensed under a Creative Commons Attribution 4.0 International License.

Read Full License 


\section{Abstract}

Background: Globally 1.13 billion peoples were living with hypertension, Out of this two-thirds of them were living in low and middle-income countries. In Ethiopia, Non Communicable Disease deaths are estimated at around $42 \%$. However, it remain widely undetected and poorly controlled. To resolve these, lifestyle modification approach that often overlooked are corner stone of the prevention and management of hypertension.

Objective: To assess lifestyle modification practice and associated factors among hypertensive patients in selected hospitals in West Arsi Zone, Oromia Regional, Ethiopia December 7 to 21, 2019.

Method: Hospital-based cross-sectional study was conducted in the selected public hospital among 299 hypertensive patients. Systemic random sampling method were used to select the study participants. Data were collected by face-to-face interviews using a structured questionnaire by trained data collectors. Data were analyzed using descriptive statistics and multivariate logistic regression method to identify predictors of the outcome $(\mathrm{p}<0.05)$.

Results: Of the total participants, only $25.2 \%$ (95\% Cl: $18.8-32.9)$ of the patients were practice recommended lifestyle modifications. Patients Age older than 65 years (AOR=2.9, 95\% $\mathrm{Cl}$ : 1.17-7.0), the patients with 2-5 years' time since diagnoses hypertension ( $A O R=0.26,95 \% \mathrm{Cl}: 0.07-0.9$ ), multiple comorbidity (AOR=2.7, 95\% Cl: 1.25-5.8) and their knowledge on hypertension management ( $A O R=14.6,95 \%$ Cl: 4.6-45.9) have an independently associated with recommended lifestyle modification.

Conclusion: Lifestyle modification practices among hypertensive patients were low in this study. Age, comorbidity, time since diagnoses of hypertension and knowledge of lifestyle were identified as predictors of the outcome.

\section{Introduction}

Hypertension is defined as when increased blood pressure, the force of blood flowing through blood vessels is consistently too high. Which occurs when systolic blood pressure is greater than or equals to $140 \mathrm{mmHg}$ or diastolic blood pressure greater than or equals to $90 \mathrm{mmHg}$. So that, hypertension is when blood pressure is reading 140/90 mmHg (American heart association, 2017,). High blood pressure, also known as hypertension, is a major contributor to the global disease burden and was responsible for 17.9 million deaths each year globally. However, it remain widely undetected, undertreated and poorly controlled. Globally 1.13 billion peoples were living with hypertension, these means 1 in 4 men and 1 in 5 women had hypertension. Out of this two-thirds of them were living in low and middle-income countries (WHO, 2019).

The prevention and management of hypertension are major public health challenges, (Joint, 2004). For example, globally only fewer than 1 in 5 people with hypertension have the problem under control. These is due to the sharing of four major risk factors: tobacco use, unhealthy diets, harmful use of alcohol, and 
physical inactivity. To address this World Health Organization (WHO) developed an action plan to help translate these commitments into action. This global action plan for prevention and control of NCDs for 2013-2020 emphasizes addressing population-based risk factors and the integrated management of NCDs at the primary healthcare level which recommended lifestyle modification for hypertensive patients (World Health Organization, 2013). As member state of the WHO, Ethiopia adopted the global strategy and developed the national NCD strategy for 10 years (FMOH, 2014).

But fewer is known about magnitude health lifestyles since many of the study were conducted on NCD especially Hypertension in Ethiopia were focus on the pharmacological managements of hypertension and its prevalence but not on non-pharmacological managements (lifestyles modification). That means there are only few studies done on the practice of lifestyles modification and associated factors of hypertension to show the gap and magnitude of the problem in this study area.

So these study that considers the practice of lifestyles modification and associated factors will guide actions to initiate for greater practice of good lifestyle modification among the hypertensive patients by providing the evidence to understanding the magnitude of the problem. So this study was to assess adherence to lifestyle modification practice and its associated factors among diagnosed hypertensive patients in the study area.

\section{Method And Material}

\section{Study area and period}

The study was conducted in West Arsi zone on selected public hospitals. West Arsi Zone found in Oromia regional state, Ethiopia. It is located $251 \mathrm{~km}$ from Addis Ababa. The zone has 13 rural woredas and 2 administrative towns with a total population of 2,696,430 male 1330488 and female 1365942. Moreover, divided into three main agro-climatically zones, highland, midland, and lowland, which comprises of $45.5 \%, 39.6 \%$, and $14.9 \%$ respectively(Abu et al., 2018). Data will be collected from December 7 to 21 , 2019.

\section{Study design}

Hospital based cross-sectional study was conducted.

\section{Source population}

All hypertensive patients who were on follow up at hospitals in West Arsi Zone

\section{Study population}

Randomly Selected hypertensive patients who fulfilled the inclusion criteria's and were available during the time of data collection.

\section{Inclusion and exclusion criteria}


All hypertensive patients who are 18 years and older, and on medical treatment (antihypertensive) at least for 1 months period before commencement of the study was recruited were included and Patients with cognitive impairment and those less than 18 years old were immediately excluded from the study.

\section{Sample size determination}

Sample size was calculated using a single population proportion formula by assuming that $23 \%$ proportion of the patients practiced lifestyle modifications (Mengistu et al., 2017) with 95\% confidence interval and $5 \%$ margin of error. Therefore, $272+(272 \times 10 \%)$ non response rate $=299$ hypertensive patients was included in the study.

\section{Sampling procedure}

In the zone, there are 7 hospitals that offer chronic follow-up services. First, out of 7 public hospitals, three was selected by simple random sampling. Then, the sample size was allocated to three hospitals proportionally (based on the number of patients reporting per month). Study subjects were selected by using systematic random sampling method; every second hypertensive patient visiting the facilities at chronic follow-up departments who were known to be hypertensive.(figure :3)

\section{Variables}

\section{Dependent variable}

The practice of lifestyles modifications

\section{Independent variables}

- Socio-Economic variables: Age, sex, income, marital status, educational status, religion, occupation, ethnicity, residence.

- Health profile of the patients: - Time since diagnosis, presence of co-morbidity, family history of hypertension.

- Individual factors: - knowledge of lifestyle modification practice.

\section{Data collection method}

Data was collected using standardized pre-tested interviewer administered questionnaire. Which was adapted from hypertension self-care practice questions recommended by joint national committee ( JNC 7) and WHO STEPS questionnaires(WHO,2016). The questionnaire was translated into Afan Oromo and back to English by language experts to ensure its consistency. The interview was conducted by eight BSc Nurse by using face to face interview method and two health officer supervisor was assigned to each hospital. The socio-demographic, health profiles of participants, Physical characteristics (height and weight) were measured. Weight and height of the patients was measured and BMI was calculated and 
classified using WHO guideline as normal weight, overweight and obese. Weight and height measurements was taken during data collection. In addition, the patient medical record was reviewed to collect data of co-morbidity and time since diagnosis of hypertension.

\section{Operational definition}

Lifestyle modification is a practice which was recommended by JNC 7 as non-pharmacological managements of hypertension measured using physical exercise, low salt diet, and moderation of alcohol intake, stop smoking, and maintaining health weight.

Adherence to lifestyle modifications practice: Were Measured based on respondents who adhere to (DASH) diet they usually or always consumed a diet rich in vegetables, grains and fruits; rarely or never consumed salt at least 3 times per week, aerobic exercise for $>30$ minutes per day; at least three times per week, stop smoking, and Keep daily alcohol intake below $30 \mathrm{~mL}$ net Alcohol according to JNC 7 recommendations. In this study the respondents who adhere to all this five healthy lifestyle were considered as adherent unless non-adherent.

Co-morbidity: respondents with one or more other medical condition in addition to hypertension

Diet-related adherence: Who usually or always consumed a diet rich in vegetables, fibers wholegrain, protein and fruits; rarely or never consumed salt; at least 3 times per week.

Exercise-related adherence: Such as running, riding bicycle, swimming and other aerobic exercise for $>30$ minutes per day; at least five times per week.

Smoking-related adherence: respondents who self-reported, they either never smoked or stopped smoking before 12 months.

Salt-related Adherence: The daily consumption of salt less than $\mathbf{5 g}$ or $\mathbf{1}$ teaspoon or never consume per food palate

Alcohol -related adherence: Either never consumed alcohol or Keep daily alcohol intake below $\mathbf{3 0} \mathbf{~ m L}$ net Alcohol.

Body mass index: calculated from the weight and height $(\mathrm{kg} / \mathrm{m} 2)$ normal weight $(18.5 \leq \mathrm{BMI}<24)$, overweight $(24 \leq \mathrm{BMl}<28)$, and obese $(\mathrm{BMI} \geq 28)(\mathrm{WHO}, 2016)$

Knowledge of healthy lifestyle: Respondents with score above the mean value on hypertension evaluation of lifestyle and management (HELM) scale were taken as having good knowledge about lifestyle modification.

\section{Data Quality Assurance}


Both the data collectors and supervisors were trained for two days on the objective and methodology of the research, data collection approach. The questionnaire was translated to Afaan Oromo language and back-translated into English by another person to check for consistency. A pretest was conducted in $15(5 \%)$ of the samples in a health care institution that was not included in the final study. The data collection instruments were assessed for completeness, consistency, and applicability and was ratified accordingly. Double data entry was done by two data clerks and consistency was checked. Finally, multivariate analysis was done to control all possible confounders. The study procedures was protect the patient's privacy by allowing anonymous and voluntary participation.

\section{Data Processing and Analysis}

Data were coded, checked, cleaned and entered into Epidata version 3.1 software, then exported to SPSS version 24.0 software for analysis. Data was checked for incomplete and inconsistent before analysis. Bivariate analysis was used to check associations between independent and dependent variables to identify factors which was associated with the outcome variable. Those variables which was found to have an association $(p<0.25)$ with the outcome variable was entered to multivariate logistic regression to test for independent association. The association between the different independent variables in relation to dependent was measured using odds ratios and $95 \%$ confidence interval $(\mathrm{Cl})$ and $\mathrm{P}$ values below 0.05 were considered to be statistically significant.

\section{Ethical consideration}

Ethical clearance was obtained from Institutional Health Research Ethics Review Committee (Ref. No. IHRERC/119/2020) of the College of Health and Medical Science Harar Campus and an official letter was sent to the selected public hospitals. After getting permission from the hospitals to participate in the study, informed, voluntary, written and signed consent was obtained for willingness of both head of hospitals and patients to participate. The patients $₫$ privacy was maintained by conducting the interview in a private place and they will be informed that there won't be any incentive or harm for their

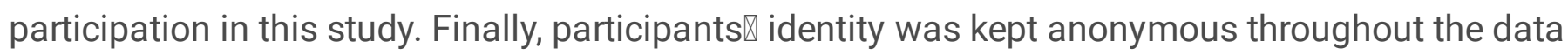
collection and analysis process.

\section{Results}

\section{Socio-demographic Characteristics of Study Participants}

A total 299 hypertensive patients were included in the study with response rate of $98 \%$. The mean age \pm standard deviation of the participant was $55 \pm 13.3$ years. More than half, $172(57.4 \%)$ of the study participants were male, and $213(71.3 \%)$ were married. Over 1 in five of respondents had no formal education. Over one in five (21.8\%) and $58(23.8 \%)$

Participants were government employee and in merchant, respectively. over three-quarter $(76.2 \%)$ were Oromo Ethnicity and 121(40.6\%) were Muslims. (Table 1$)$. 


\section{Clinical characteristics of Study participants}

From participants, the majority $144(48 \%)$ of them were less than 2 years since when they are diagnosed as hypertensive patients and 62(20.8\%) patients diagnosed before 6 years on treatments. From the total, $158(53 \%)$ patients were overweight whereas $30(9.9 \%)$ were Obese. Over Two third $(62.3 \%)$ of respondents had co-morbidity especially Diabetic mellitus and $117(39.1 \%$ ) has family history of hypertension. (Table 2)

\section{Adherence to recommended lifestyle modification practices among hypertensive patient}

According to the finding of these study, $25.2 \%$ ( $95 \% \mathrm{Cl}$ : 18.8-32.9) of patients practice all recommended lifestyle modifications. As age increase the adherence to healthy lifestyles were also increase (Figure 1 \& 2). Of the total participants, $63.4 \%$ do not engage in regular physical exercise for at least 3 days of the week with a minimum of 30 min duration. One hundred forty five $(48.5 \%)$ of study subjects were adhere to limitation of alcohol intake and more than half (52.5\%) of them practices recommended low salt diet. Additionally, majority of participants were not ever smoking $225(75.2 \%)$ and $10 \%$ of hypertensive patients were smoke cigarettes. Nearly half, $142(47.5 \%)$ of study participants were practicing recommended health weight managements. Only $45 \%$ of respondent has knowledge's of recommended lifestyle modification practices (Table 3)

\section{Factors associated with adherence to lifestyle modifications practices}

The results of the bivariate analysis shows that age, Co-morbidity, time since diagnosis of Hypertension, those who has formal education and knowledge of lifestyle modification were become significant association with dependent Variable.

After controlling possible confounding effects of other covariates, age, time since diagnosis, co-morbidity and knowledge about the disease were significantly affecting the adherence to healthy lifestyle modification among hypertensive patients. Patients older than 65 years was 3 times more likely to be adherent to recommended healthy lifestyle modification practices than patients younger than 64 years old (AOR=2.9, 95\% Cl: 1.17-7.0). Those respondents who had good knowledge were 15 times more likely to be adherent (AOR=14.6, 95\% Cl: 4.6-45.9) compared to the non-knowledgeable respondents. Additionally, the patients with $2-5$ years since times of diagnosis were $74 \%$ times less likely practicing healthy lifestyle modification ( $\mathrm{AOR}=0.26,95 \% \mathrm{Cl}: 0.07-0.9)$ as compared to those on treatment for greater than 6 years of treatment. Also, patients who were with co-morbidity were 2.7 more likely to practice healthy lifestyle modification (AOR=2.7, $95 \% \mathrm{Cl}: 1.25-5.8$ ) as compared to those without comorbidity (Table 4).

\section{Discussion}

Even though healthy lifestyle modification is one of important hypertension management, poor adherence to healthy lifestyle is one of the reasons for serious complication and uncontrolled 
Hypertension in addition to wastage of health care resources. So, Control of hypertension requires both pharmacological and non-pharmacological treatments. Since the adherence to healthy lifestyle and medication is ultimate strategies to control hypertension, this study was aimed to asses' lifestyle modification practices and associated factors among diagnosed hypertensive patients.

According to the Main intention results of these study only 75(25.2\%) participants were practicing the recommended lifestyle modification. Nearly comparable results $27.3 \%$ Adherence were revealed according to study conducted in Ethiopia in Durame and Nigist Elleni memorial hospital (Siyum et al., 2017). In contrast, the study conducted in USA shows that $50 \%$ of participants were engaged in healthy lifestyle practices (Abu et al., 2018). This might be due to difference educational back ground of patients and level of awareness about lifestyle modification and its advantages. It also might be due to patients relay only on medication without considering effects of healthy lifestyle modification on hypertension control.

From the participants three fourth of them were non-smokers and half of them were abstained from any type of alcohol drinking or less than $30 \mathrm{~mL}$ net alcohol daily consumption. This is supported by study finding which is done in Malaysia and Ghanaian on hypertensive patients (Afia et al., 2014, Tahmina et al., 2018). This could be due to social and cultural practices that discourage alcohol drinking and smoking.

In these study less than half of participants were adherent to Performing recommended physical exercise for 30 minute per day. But similar studies results from India and Thailand found (53\%) and (40\%) respectively (Lipilekha et al., 2017, Zahid et al., 2017). The possible explanation could be related to low awareness, socio-economic variation and lack of organized setup in living areas in developing countries like Ethiopia.

Among lifestyle modification two fourth of the participants practicing limited salt diet ( $\leq 1 \mathrm{tsp} /$ day of table salt) and nearly half of them were practicing maintaining's of a healthy weight using recommended diets (DASH) including more fruits, vegetable, grains, and beans in the diet and reading nutritional facts on food labels. Similar study finding from Saudi Arabia shows that the $79.3 \%$ of patient practice low salt diet and 59.9\% practicing maintaining's of a healthy weight (Lama et al., 2017). The discrepancy between these study and the study from Saudi Arabia could be due to the economic class, the difference in the dietary habits and easy access of recommended diets.

Older age respondents were found to be more adherent to health lifestyle than younger age groups. The study from kingdom of Sued Arabia support this finding in that age $>65$ years old more likely in practicing recommended lifestyle modification (Abubaker, 2015). This could be due to older persons have more education and cognitive function and have more comorbidities which may make them visit health care providers more frequently. Another explanation might be younger patients were less likely eager to control their blood pressure by practicing the lifestyle modification. 
On the other hand, Knowledge is also significantly associated with adherence to healthy lifestyle modification. Knowledgeable hypertensive patients about healthy lifestyle were more adherent to recommended healthy lifestyle modifications. This is supported by the finding from the study in Ethiopia at the cardiac clinic of Ayder comprehensive specialized hospital and USA ,Maryland (Abu et al., 2018, Yirga et al., 2019). Explanation might be as knowledge status increase practice and motivation of lifestyle modification practice will also increase. It may be due to access to information sources like fosters, leaflets and similar written material about hypertension managements and controls

A study conducted in Addis Ababa found out that people with comorbidities were more likely to be adherent to healthy lifestyle recommendations (Abu et al., 2018, Mengistu et al., 2017). Surprisingly the finding of these study also depicting respondents having one or more comorbidity were found more likely to be adherent to all the healthy lifestyle recommendations. Patients with comorbidities visit health care providers more frequently and pay more attention to their health conditions, as this was evidenced by better adherence to lifestyle modifications.

Hypertensive Patients with greater than 6 years times since diagnoses were more likely to practice healthy lifestyle modification as compared to those on treatment for less 2 years treatment. This finding is supported by different studies that show patients on longer duration of treatment had good lifestyle modification practice (Durai and R, 2015, Siyum et al., 2017). This might be due to continued counseling' and health education.

The limitation is that the study didn't include hypertensive patients who were attending follow up in private health facilities in study area. Also, research methodologies involving self-reported measures depend largely on individuals $₫$ memory, and recall bias may exist.

\section{Conclusion}

This study revealed lifestyle modification practice is low among the hypertensive patients. Of the studied variables, age, duration of the hypertension diagnosis, knowledge about lifestyle and comorbidity were factors significantly associated with health lifestyle modification practice. Out of this factors duration of the hypertension diagnosis (time since diagnosis) were negatively associated with lifestyle modification and the rests age, knowledge about healthy lifestyle and comorbidity were positively associated with lifestyle modification.

\section{Abbreviations}

AOR: Adjusted Odd Ratio, BP: Blood pressure, HELM: Hypertension Evaluation of Lifestyle and Management Scale. CVD: Cardiovascular Disease, DALY: Disability Adjusted life years, DASH: Diet Allowance to stop Hypertension, DBP: Diastolic blood pressure, ETB: Ethiopian birr, FMO: Federal ministry of health, HELM: Hypertension Evaluation of Lifestyle and Management Scale, JNC7: 7the Joined National Committee .NCD: Non communicable Disease, SBP: Systolic blood pressure 


\section{Declarations}

\section{Author's contributions}

HW, TG and HS made a substantial contribution to the conception design, acquisition and interpretation of data. HW drafted the manuscript and carried out rigorous editorial work. All authors revised the paper critically for the intellectual contents. All authors read and approved the final manuscript.

\section{Author's information}

$\mathrm{HW}^{1,2}$ Shala District health office West Arsi Zone, Oromia, Ethiopia. $\mathrm{TG}^{1}, \mathrm{HS}^{1}$ College Health and Medical science, Haramaya University, Harar, Ethiopia.

Conflict of interest: The authors declare that they have no competing interests.

\section{ACKNOWLEDGEMENTS}

First of all I am very grateful to God. Next, I would like to thank both my advisors Associate Professor Tesfaye Gobena and Mr.Hirbo Shore (MPH) for their unreserved guidance and constructive suggestions and comments, at each step of the research development. Next I would like to thank the participants of this thesis for their cooperation and Haramay University for giving me this chance.

\section{References}

ABUBAKER, E. 2015. Level Of Adherence To Lifestyle Changes And Medications Among Male Hypertensive Patients In Two Hospitals In Taif; Kingdom Of Saudi Arabia International Journal of Pharmacy and Pharmaceutical Sciences 7, 168-172

ABU, H., ABOUMATAR, H., CARSON, K., GOLDBERG, R. \& L., C. 2018. Hypertension knowledge, heart healthy lifestyle practices and medication adherence among adults with hypertension. European Journal for Person Centered Healthcare, 6, 108-114.

AMERICAN HEART ASSOCIATION 2017,. Guideline for the Prevention, detection, evaluation and management of high Blood Pressure in adults,.

AFIA, T, F., O, M. \& S, I. I. 2014. Ghanaian hypertensive patients understanding of their medicines and life style modification for managing hypertension. International Journal of Pharmacy and Pharmaceutical Sciences, 6, 165-170

DURAl, V. \& R, A. 2015. Knowledge and Practice on lifestyle modifications among males with hypertension. Indian journal of community health, 27, 143-149.

FMOH 2014. National strategic action plan for the prevention and control of NCDs in Ethiopia 2014 2016. . 
JOINT, T. S. R. O. T. C. N. 2004. prevention, detection, evaluation, and treatment of high blood pressur. National Institutes of Health, U.S. Department of Health and Human Services.

LAMA, A., ALSHIMAA, A., MARADI, A. \& RANA, M. 2017. Awareness and Knowledge on Hypertension and its Self-Care Practices Among Hypertensive Patients in Saudi Arabia. Annals of International Medical and Dental Research,, 3, 58-63.

LIPILEKHA, P., KALYAN, K., SUMITRA, P. \& TRILOCHAN, S. 2017. Lifestyle Pattern and Hypertension Related Knowledge, Attitude and Practices among Diagnosed Patients of Hypertension Attending a Tertiary Care Hospital. Journal of Cardiovascular Disease Research, 8, 108-111.

MENGISTU, D., TIBEBU, A. \& NEGESA, L. 2017. Adherence to recommended lifestyle modifications and factors associated for hypertensive patients attending chronic follow-up units of selected public hospitals in Addis Ababa, Ethiopia,. Patient Preference and Adherence, 11, 323-330.

SIYUM, E., KELBISO, L. \& OLANA, R. 2017. Lifestyle modification practice andassociated factors among diagnosedhypertensive patients in selected hospitals,South Ethiopia, . Clinical Hypertension 23, 1-9.

TAHMINA, N, H., K, K. \& M, R. 2018. Lifestyle modification practice in rural community at Kedah in Malaysia. Journal of Basic, Clinical and Applied Health Science, 1, 19-26

WORLD HEALTH ORGANIZATION, G. 2013. A global brief on hypertension.

WHO 2005. Clinical guidelines for the management of hypertension

WHO 2016. WHO STEPwise Approach to Chronic Disease Risk-Factor Surveillance

YIRGA, L., SEID, I., KASSA, T. D. \& ASGEDOM, S. W. 2019. Practice and predictors of self-care behaviors among ambulatory patients with hypertension in Ethiopia. PLOS ONE 14(6), 1-16.

ZAHID, H. M., MOST, L., SATYA, P. \& MARIF 2017. Knowledge, attitude and practice of life style modification in the management of hypertension. Obese Eat Disorder, 3, 21.

\section{Tables}

Table 1 Socio-demographic characteristics of participants West Arsi Zone, Ethiopia, 2019 


\begin{tabular}{|c|c|c|}
\hline Variables & Frequency & Percent (\%) \\
\hline \multicolumn{3}{|l|}{ Age in year } \\
\hline (18-40) Early a dulthood & 50 & 16.8 \\
\hline (41-64 ) Middle Adulthood & 132 & 44.1 \\
\hline ( $\geq 65$ ) Late Adulthood & 117 & 39.1 \\
\hline \multicolumn{3}{|l|}{ Sex } \\
\hline Female & 127 & 42.6 \\
\hline Male & 172 & 57.4 \\
\hline \multicolumn{3}{|l|}{ Marital status } \\
\hline Single & 8 & 3 \\
\hline Divorce & 39 & 12.9 \\
\hline Widowed & 39 & 12.9 \\
\hline Married & 213 & 71.3 \\
\hline \multicolumn{3}{|l|}{ Educational status } \\
\hline Secondary & 46 & 15.3 \\
\hline Primary & 47 & 15.8 \\
\hline Able to read and write & 56 & 18.8 \\
\hline No formal education & 63 & 20.8 \\
\hline College and above & 87 & 29.2 \\
\hline \multicolumn{3}{|l|}{ Employment status } \\
\hline Daily laborer & 27 & 9.4 \\
\hline Housewife & 36 & 11.9 \\
\hline Retired & 42 & 13.9 \\
\hline Private employee & 58 & 19.3 \\
\hline Government employee & 65 & 21.8 \\
\hline Merchant & 71 & 23.8 \\
\hline \multicolumn{3}{|l|}{ Religion } \\
\hline Other(wakefata,jovh) & 15 & 3.5 \\
\hline Catholic & 28 & 6.4 \\
\hline Protestant & 74 & 16.8 \\
\hline Muslim & 182 & 40.6 \\
\hline Orthodox & 61 & 32.6 \\
\hline \multicolumn{3}{|l|}{ Ethnicity } \\
\hline Wolayita and Others & 28 & 9.4 \\
\hline Amhara & 43 & 14.4 \\
\hline Oromo & 228 & 76.2 \\
\hline \multicolumn{3}{|l|}{ Average monthly income } \\
\hline$<999$ ETB & 7 & 2.5 \\
\hline 1000-1999ETB & 40 & 13.4 \\
\hline No regular income & 61 & 20.3 \\
\hline 2000-2999ETB & 86 & 28.7 \\
\hline$>3000 \mathrm{ETB}$ & 105 & 35.1 \\
\hline
\end{tabular}

Table 2:- Health profiles of respondents among hypertensive patients attending chronic follow up units of selected hospitals in West Arsi zone, Ethiopia, 2019 


\begin{tabular}{llcc}
\hline Variables & categories & Frequency & percent (\%) \\
\hline Time since diagnosis & less than 2 years & 144 & 48 \\
\cline { 2 - 4 } & 2-5 years & 93 & 31.2 \\
\hline & greater than 6 years & 62 & 20.8 \\
\hline Body mass index $\left(\mathrm{kg} / \mathrm{m}^{2)}\right.$ & Normal(18-24) & 111 & 37.1 \\
\hline & Overweight(24-28) & 158 & 53 \\
\hline & Obese $(\geq 28)$ & 30 & 9.9 \\
\hline Multiple Comorbidities & present & 186 & 62.3 \\
\hline \multirow{2}{*}{ Family history of hypertension } & Absent & & 37.6 \\
\hline & Yes & 113 & 39.1 \\
\hline & No & 182 & 60.9 \\
\hline
\end{tabular}

Table 3 Adherence to recommended lifestyle modifications practice among hypertensive patients attending chronic follow up units of selected hospitals in West Arsi zone, Ethiopia, 2019 


\begin{tabular}{|c|c|c|}
\hline Variables & frequency & Percent (\%) \\
\hline \multicolumn{3}{|l|}{ Maintain a healthy weight } \\
\hline Good & 142 & 47.5 \\
\hline Bad & 157 & 52.5 \\
\hline \multicolumn{3}{|l|}{ Limit alcohol intake } \\
\hline Yes (daily net alcohol intake below $30 \mathrm{~mL}$ ) & 145 & 48.5 \\
\hline No (daily net alcohol intake Above 30 mL) & 154 & 51.5 \\
\hline \multicolumn{3}{|l|}{ Perform recommended physical exercise ( $30 \mathrm{~min} /$ day) } \\
\hline Yes & 109 & 36.6 \\
\hline No & 190 & 63.4 \\
\hline \multicolumn{3}{|l|}{ Status of tobacco use } \\
\hline Ever not used & 225 & 75.2 \\
\hline Still smoking & 30 & 10 \\
\hline Stopped smoking & 44 & 14.8 \\
\hline \multicolumn{3}{|l|}{ Practice recommended low salt diet } \\
\hline Yes (about $\leq 1 \mathrm{tsp} /$ day of table salt). & 157 & 52.5 \\
\hline No (greater than 1 tsp/day of table salt). & 142 & 47.5 \\
\hline \multicolumn{3}{|l|}{ Adherence to all recommended healthy lifestyle } \\
\hline Adherent & 75 & 25.2 \\
\hline Non adherent & 224 & 74.8 \\
\hline \multicolumn{3}{|l|}{ Knowledgeable about healthy lifestyle } \\
\hline poor & & 5 \\
\hline good & & 5 \\
\hline
\end{tabular}

Table 4: - Predictors of lifestyle modification practices among hypertensive patients attending chronic follow up units of selected hospitals in West Arsi zone, Ethiopia, 2019 


\begin{tabular}{|c|c|c|c|c|}
\hline \multirow[t]{2}{*}{ Variables } & \multirow{2}{*}{$\begin{array}{l}\text { Healthy } \\
\text { Adherent } \\
\text { N (\%) }\end{array}$} & \multirow{2}{*}{$\begin{array}{l}\text { Lifestyle adherence } \\
\text { Non-adherent N (\%) }\end{array}$} & \multirow[b]{2}{*}{$\operatorname{COR}(95 \% \mathrm{CI})$} & \multirow[b]{2}{*}{ AOR(95\%CI) } \\
\hline & & & & \\
\hline \multicolumn{5}{|l|}{ Age in year } \\
\hline $18-40$ & $22(29.4)$ & $34(15.2)$ & & 1 \\
\hline $41-64$ & $19(25.5)$ & $92(41.1)$ & $0.59(0.4-3.6)$ & $1.4(0.4-4.6)$ \\
\hline$\geq 65$ & $34(45.1)$ & $98(43.7)$ & $1.6(1.01-4.97)^{*}$ & $2.9(1.17-7.0)^{*}$ \\
\hline \multicolumn{5}{|l|}{ Sex } \\
\hline Male & $35(47)$ & $90(40.3)$ & 1 & \\
\hline Female & $40(53)$ & $134(59.6)$ & $0.764(0.70-2.48)$ & $1.13(0.5-2.3)$ \\
\hline \multicolumn{5}{|l|}{ Marital status } \\
\hline Married & $59(78.4)$ & $154(68.8)$ & 1 & \\
\hline Divorce & $10(13.7)$ & $34(15.2)$ & $0.76(0.40-2.67)$ & $0.9(0.36-2.6)$ \\
\hline Widowed & $6(8)$ & $36(15.9)$ & $2.1(0.68,-6.5)$ & $1.9(0.6-6.5)$ \\
\hline \multicolumn{5}{|l|}{ Educational status } \\
\hline No formal education & $6(7.8)$ & $56(25.1)$ & 1 & \\
\hline Formal education & $69(92.1)$ & $168(74.8)$ & $3.8(1.15-9.57)^{*}$ & $1.7(0.5-5.6)$ \\
\hline \multicolumn{5}{|c|}{ Average monthly income } \\
\hline no regular income & $10(13.7)$ & $50(22.5)$ & 1 & \\
\hline 1000-1999ETB & $6(8)$ & $42(18.5)$ & $0.40(0.16-1.1)$ & $1 \quad(0.26-4.4)$ \\
\hline 2000-2999ETВ & $28(37.2)$ & $58(25.8)$ & $0.35(0.21-0.58)$ & $0.4(0.15-1.2)$ \\
\hline$>3000 \mathrm{ETB}$ & $31(41)$ & $74(33)$ & $1.18(0.3-4.5)$ & $0.48(0.17-1.3)$ \\
\hline \multicolumn{5}{|c|}{ Knowledgeable about healthy lifestyle } \\
\hline Poor & $16(21.5)$ & $148(66.2)$ & & 1 \\
\hline Good & $59(78.4)$ & $76(33.7)$ & $7.1(3.4-15.07)^{*}$ & $14.6(4.6-45.9)^{* *}$ \\
\hline \multicolumn{5}{|l|}{ Time since diagnosis } \\
\hline less than 2 years & $44(58.8)$ & $99(44.3)$ & & 1 \\
\hline $2-5$ years & $19(25.5)$ & $74(33.1)$ & $0.57(0.074-0.85)^{*}$ & $0.26(0.07-0.9)^{*}$ \\
\hline greater than 6 years & $12(15.6)$ & $50(22.5)$ & $0.86(0.272-2.76)$ & $0.4(0.1-1.45)$ \\
\hline \multicolumn{5}{|c|}{ Multiple Comorbidities } \\
\hline Absent & $25(31.6)$ & $126(58.6)$ & & 1 \\
\hline Present & $54(68.3)$ & $89(41.3)$ & $3.05(1.771-5.28)^{*}$ & $2.7(1.25-5.8)^{* *}$ \\
\hline
\end{tabular}

${ }^{*} A O R=$ statistically significant at $P<0.05, * * A O R=$ statistically significant at $P<0.001$,

\section{Figures}




\section{Adherence to all recommended lifestyle modification}

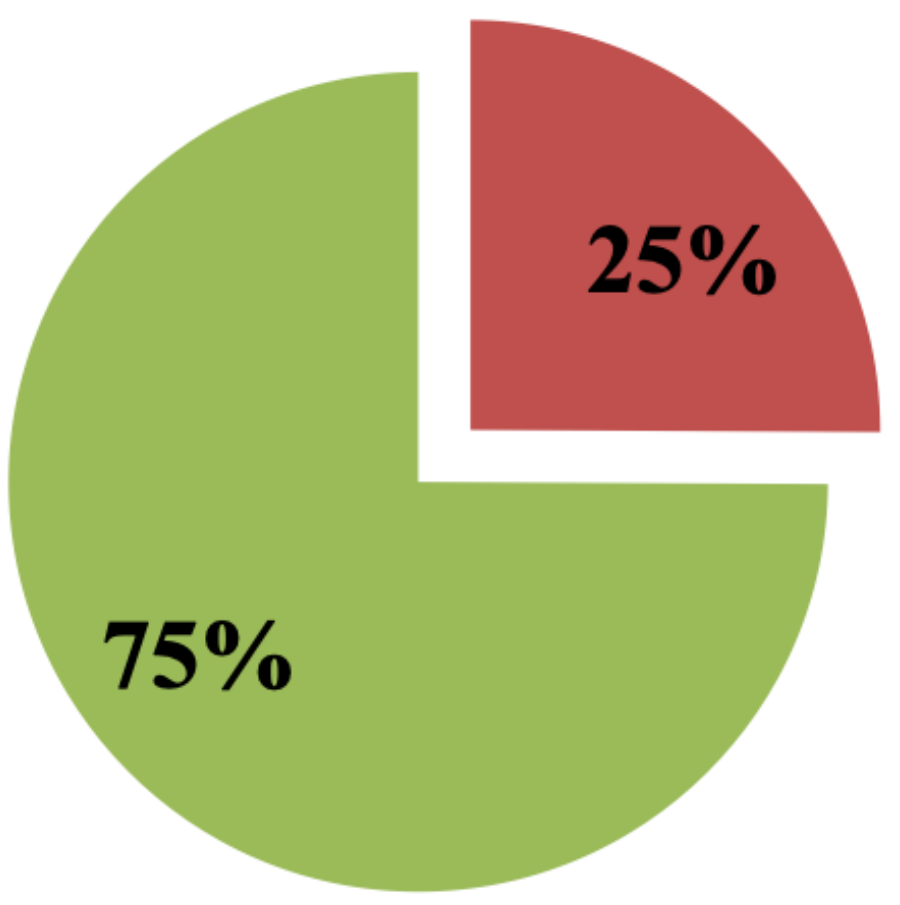

Adherent

Non adherent

Figure 1

Adherence to healthy lifestyle among hypertensive patients attending chronic follow up units of selected hospitals in West Arsi zone, Ethiopia, 2019 


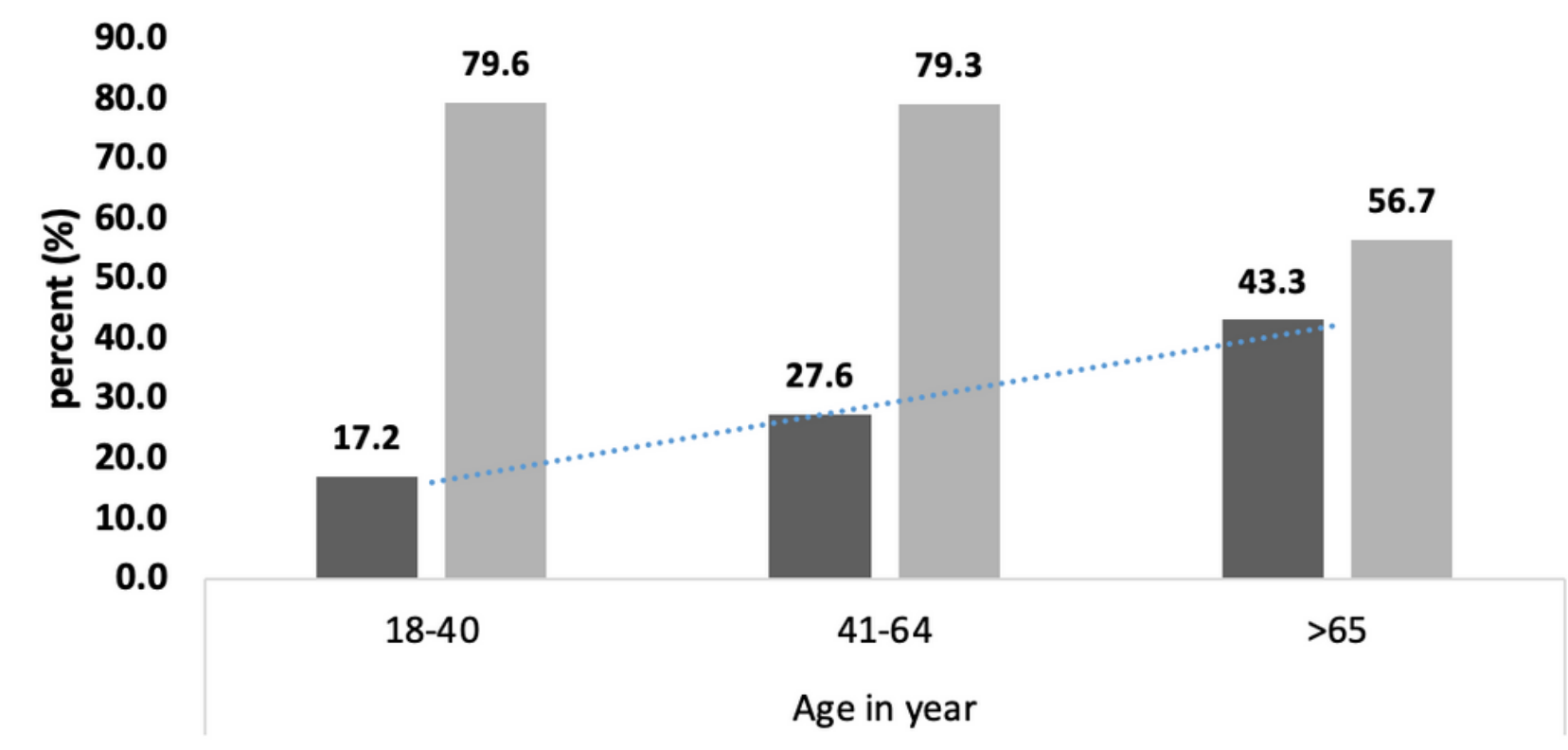

Adherent Non adherent $\quad$......... Linear ( Adherent )

Figure 2

Adherence to healthy lifestyle by age group among hypertensive patients attending chronic follow up units of selected hospitals in West Arsi zone, Ethiopia, 2019 


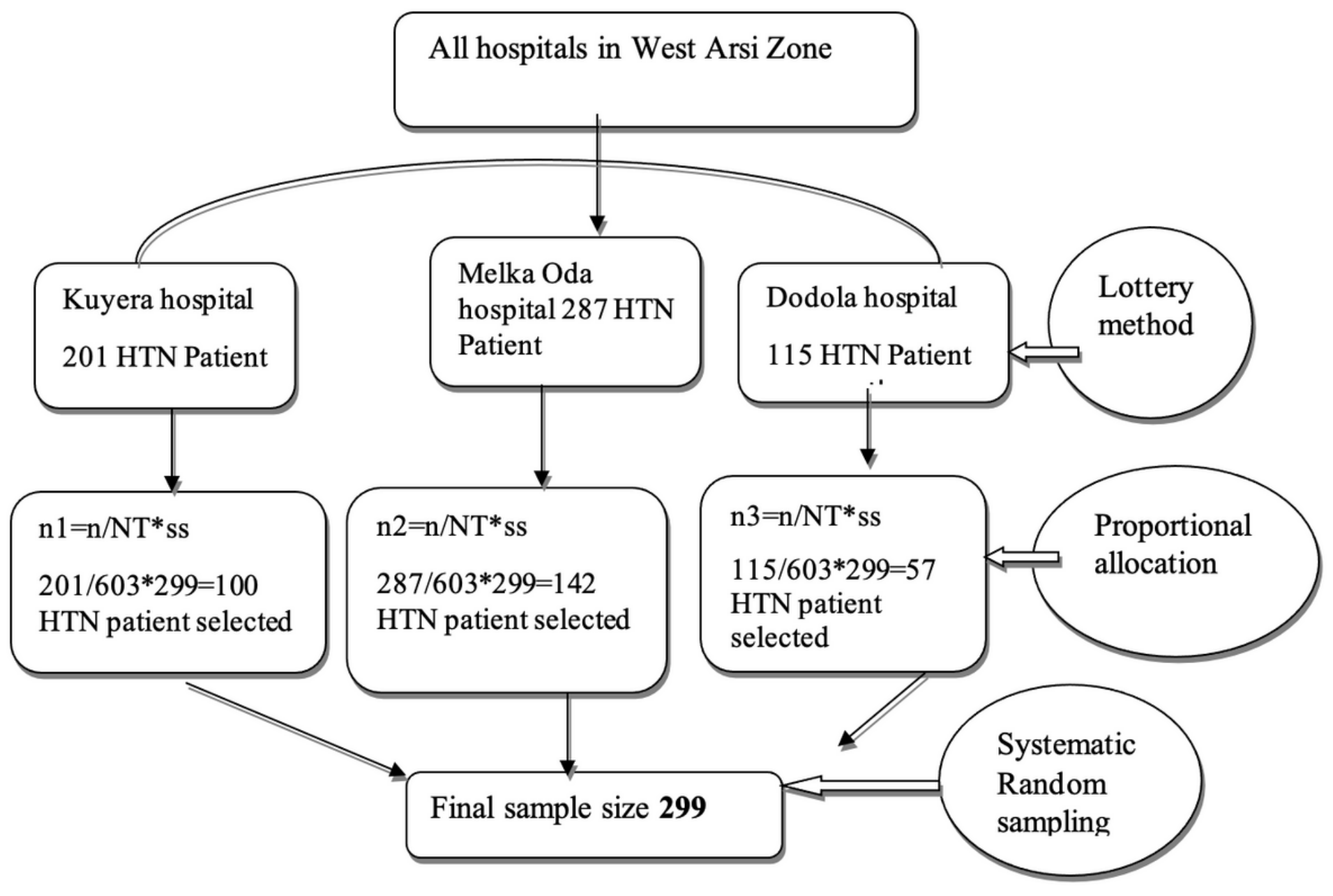

Figure 3

Schematic presentation of sampling techniques used to select study subjects from public health hospitals in West Arsi Zone, 2019 